\title{
Auscultation of Foetal Heart Rate : an Assessment of its Error and Significance
}

\author{
EVAN DAY*; LYNNE MADDERN*; CARL WOOD, † F.R.C.o.G., F.R.C.S.
}

Brit. med. F., 1968, 4, 422-424

\begin{abstract}
Cummary : Auscultation of foetal heart rate was shown $\checkmark$ to be subject to three types of error : a random error, an error biased towards normality when the heart rate is fast or slow, and an error based on the inability to count the heart rate during contractions. In spite of these limitations a clinically observed foetal heart rate of more than 160 beats per minute was shown to be associated with significantly lower Apgar scores at birth. In contrast, a steady foetal heart rate of $100-120$ beats per minute was not.
\end{abstract}

\section{Introduction}

Traditionally the diagnosis of foetal distress has been based on the clinical criteria of the presence of meconium in the liquor amnii and an abnormal foetal heart rate. However, the value of these criteria has been questioned (Hon, 1958 ; Wood and Pinkerton, 1961). More recently continuous electronic monitoring of the foetal heart rate and measurement of foetal scalp blood and base status have been used to assess the foetal condition, and the findings of a number of studies suggest they may be more reliable than clinical methods (Caldeyro-Barcia et al., 1966 ; Beard et al., 1967 ; Hon, 1967 ; Saling, 1967 ; Wood, 1968). However, as these new methods require expensive equipment and extra staff, the foetal condition will still be assessed in many hospitals by traditional methods. The present study was designed to determine the accuracy and usefulness of clinical measurement of the foetal heart rate.

\section{Methods}

Clinical foetal heart rate was recorded by hospital staff counting for periods of 30 or 60 seconds. An abnormal foetal heart rate (more than 160 or fewer than 120 beats per minute) was checked by a trained midwife and resident obstetrician. Two of us (E. D. and L. M.) also estimated the foetal heart rate by auscultation, using a stopwatch to count for 30-second periods. The monitored foetal heart rate was recorded electronically by means of an electrode applied to the foetal scalp to detect the foetal electrocardiograph (Hon, 1960). This method was accurate to \pm 6 beats per minute. Uterine activity was recorded by measurement of intra-amniotic fluid pressure by means of an open-ended catheter passed through the cervix and above the presenting part.

The study was carried out in two parts.

(1) Assessment of Error of Auscultation.-The error of auscultation was determined by comparing measurements obtained by this method with those of the electronic monitor. The overall error of the hospital staff was estimated from 126 observations made on 90 patients. With the same patients a further analysis of the error of the hospital staff was made over different ranges of foetal heart rate: (1) 130-150 beats per minute, (2) fewer than 130 beats per minute, and (3) more than

\footnotetext{
- Medical students who carried out this study during an elective period of their course.

t Professor of Obstetrics and Gynaecology.

Department of Obstetrics and Gynaecology, Monash University, Queen Victoria Hospital, Melbourne, Victoria, Australia.
}

150 beats per minute. Additional information concerning the error of auscultation was obtained by comparing the abnormalities detected by auscultation with those found by detailed analysis of the monitored foetal heart rate. In order to simplify this comparison changes in the monitored foetal heart rate (Wood et al., 1967, 1968) were grouped into three broad categories (Fig. 1). Our overall error was determined from 88 observations made in seven patients. We included one obese and one uncooperative patient in our group to avoid the possibility of a favourable bias in selecting patients.

\begin{tabular}{|c|c|c|}
\hline TYPE & \multicolumn{2}{|r|}{$\begin{array}{c}\text { FOETAL HEART RATE PATTERNS } \\
\text { IN RELATION } \\
\text { TO UTERINE CONTRACTION }\end{array}$} \\
\hline NORMAL & $\begin{array}{l}160- \\
120-\end{array}$ & Normal $120-160$ \\
\hline \multirow{4}{*}{$\begin{array}{c}2 \text { ABNORMAL WITH } \\
\text { COOD FOETAL } \\
\text { PROCNOSIS }\end{array}$} & $\begin{array}{l}160- \\
120-\end{array}$ & Fast $>160$ \\
\hline & $\begin{array}{l}160- \\
120-\end{array}$ & Slow $<120$ \\
\hline & $\begin{array}{l}160- \\
120-\end{array}$ & $\begin{array}{l}\text { Slowing } 30-60 \text { during } \\
\text { contractions } \\
\text { baseline } 120-160\end{array}$ \\
\hline & $\begin{array}{l}160- \\
120-\end{array}$ & $\begin{array}{c}\text { Slowing }>60 \text { during } \\
\text { contractions } \\
\text { baseline } 120-160\end{array}$ \\
\hline 3 ABNORMAL WITH & $\begin{array}{l}160- \\
120=\end{array}$ & $\begin{array}{c}\text { Slowing }>60 \text { during } \\
\text { contractions } \\
\text { baseline }>160\end{array}$ \\
\hline PROCNOSIS & $\begin{array}{l}160- \\
120-\end{array}$ & $\begin{array}{l}\text { Slowing consistently at end of } \\
\text { contraction }- \text { baseline } \\
\text { normal or }>160\end{array}$ \\
\hline
\end{tabular}

FIG. 1.-Diagram showing detailed analysis of monitored foetal heart rate changes and the grouping of these changes into three broad categories (types 1-3).

(2) Significance of Abnormal Clinical Foetal Heart Rate.The significance of abnormal foetal heart rate detected by auscultation was determined in 144 patients by comparing the Apgar scores of babies two minutes after birth in the following groups: controls having both a normal monitored foetal heart rate and a normal foetal scalp blood $\mathrm{pH}$; clinical foetal heart rate more than 160 beats per minute; clinical foetal heart rate fewer than 120 beats per minute; presence of meconium in the liquor ; clinical foetal heart rate more than 160 beats per minute and the presence of meconium in the liquor; clinical foetal heart rate under 120 beats per minute and the presence of meconium in the liquor. The Mann-Whitney $U$ test was used to compare the groups.

\section{Results}

\section{Assessment of Error of Auscultation}

The overall error of auscultation of the hospital staff was considerable, $20 \%$ of observations being inaccurate by more 
than \pm 15 beats per minute (Table I). In contrast, our overall error was much smaller, $1 \%$ of observations being inaccurate by more than \pm 15 beats per minute (Table II).

TABLE I.-Overall Error of Auscultation of Hospital Staff

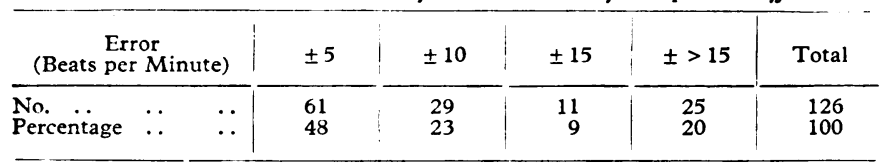

TABLE II.-Overall Error of Auscultation by Authors

\begin{tabular}{|c|c|c|c|c|c|c|}
\hline $\begin{array}{r}\text { Err } \\
\text { (Beats per }\end{array}$ & $\begin{array}{l}\text { ror } \\
\text { Minute) }\end{array}$ & \pm 5 & \pm 10 & \pm 15 & $\pm>15$ & Total \\
\hline $\begin{array}{l}\text { No. ... } \\
\text { Percentage }\end{array}$ & $\begin{array}{ll} & .\end{array}$ & $\begin{array}{l}73 \\
83\end{array}$ & $\begin{array}{l}13 \\
15\end{array}$ & $\begin{array}{l}1 \\
1\end{array}$ & $\begin{array}{l}1 \\
1\end{array}$ & $\begin{array}{r}88 \\
100\end{array}$ \\
\hline
\end{tabular}

Further analysis of the error of the hospital staff showed that it had two components. When the foetal heart rate was 130-150 beats per minute the error was random, but when the foetal heart rate was more than 150 or fewer than 130 beats per minute the error was biased, so that the measurements would tend to lie between 130 and 150 beats per minute (Fig. 2). Statistical analysis of the biased error showed that this was significant for both the fast and slow foetal heart rate groups, $\mathrm{P}<0.0028$ and $\mathrm{P}<0.0005$ respectively. Apart from the random and biased errors of auscultation, a further limitation of this method was evident when detailed analysis of the monitored foetal heart rate was made (Table III). Foetal heart rate changes in relation to a contraction which are important in determining foetal prognosis were not detected by auscultation. The monitored foetal heart rate patterns associated with a reduction in the Apgar score at birth (type 3) were found more frequently in association with a clinical foetal heart rate of more than 160 beats per minute $(P<0.03)$.

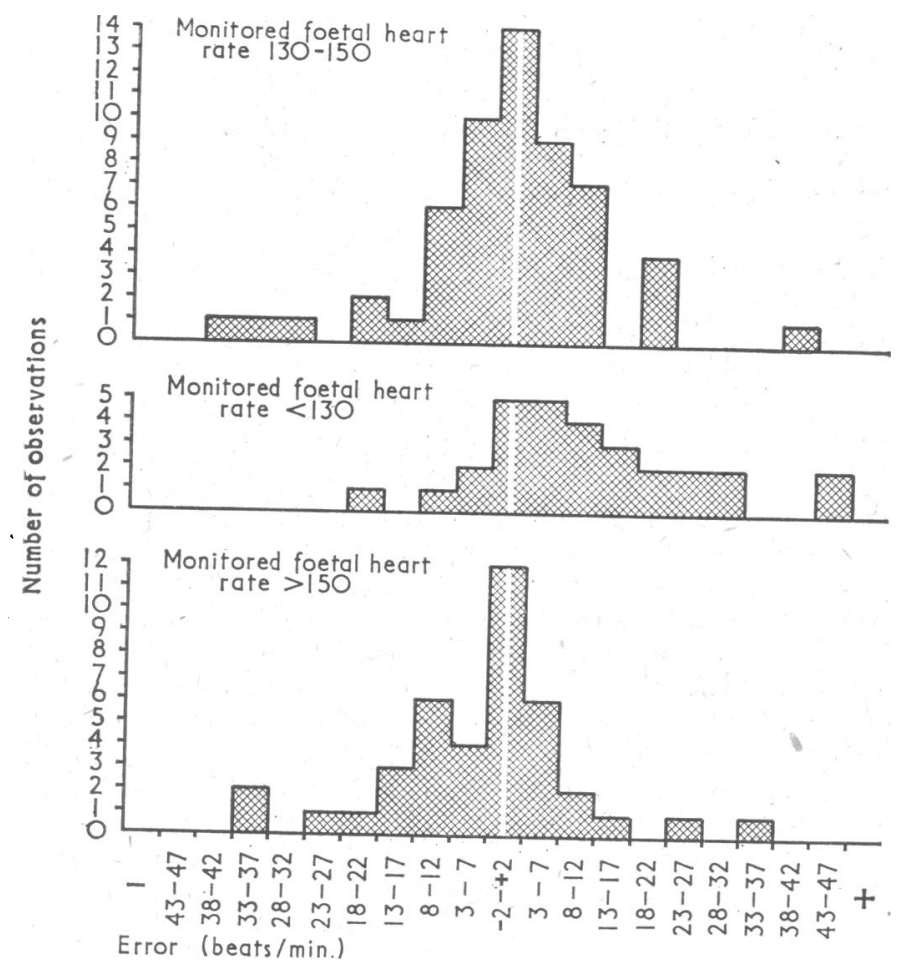

Fig. 2.-Error of auscultation of hospital staff at different foetal heart

An example of the limitations of auscultation is shown in Fig. 3, neither the rapid foetal heart rate of 165 beats per minute nor the slowing of 60 beats per minute during contractions being detected.
TABLE III.- Relation Between the Foetal Heart Rate Determined by Auscultation and Electronic Monitor

\begin{tabular}{|c|c|c|c|c|}
\hline \multirow{2}{*}{ Clinical } & & \multicolumn{3}{|c|}{ Monitor } \\
\hline & & Normal & $\begin{array}{c}\text { Abnormal } \\
\text { with Good Foetal } \\
\text { Prognosis }\end{array}$ & $\begin{array}{c}\text { Abnormal } \\
\text { with Poor Foetal } \\
\text { Prognosis }\end{array}$ \\
\hline $\begin{array}{ll}\text { Normal } \\
>160 \\
<120 \quad \ldots\end{array}$ & $\begin{array}{l}. \\
\therefore\end{array}$ & $\begin{array}{l}45 \% \\
23 \% \\
37 \%\end{array}$ & $\begin{array}{l}48 \% \\
50 \% \\
63 \%\end{array}$ & $\begin{array}{r}7 \% \\
27 \% \\
\end{array}$ \\
\hline
\end{tabular}

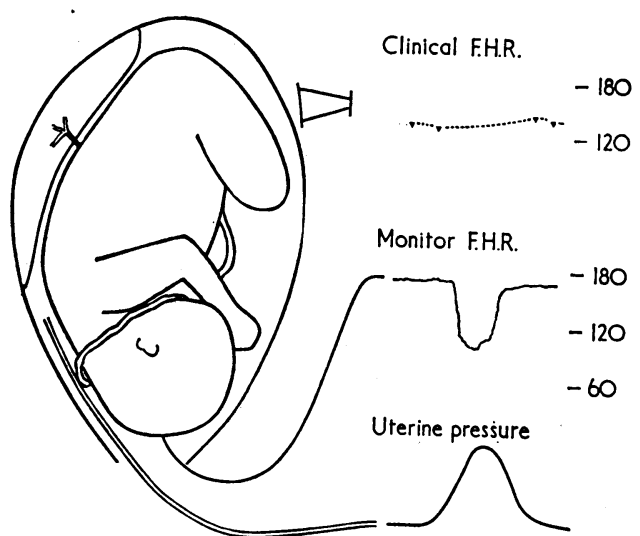

FIG. 3.-An example of two errors of clinical auscultation, the monitor showing a fast foetal heart rate between contractions and slowing during contractions.

\section{Significance of Abnormal Clinical Foetal Heart Rate}

When the foetal heart rate was more than 160 beats per minute the Apgar scores were significantly lower than both the control group $(P<0.05)$ and the group with a foetal heart rate of $90-120$ beats per minute $(\mathbf{P}<0.022)$ (Table IV). The presence of meconium did not alter this relationship, the combination of meconium in the liquor and a foetal heart rate of more than 160 beats per minute having a significantly lower distribution of Apgar scores than the presence of meconium alone $(P=0.0116)$ or the presence of meconium with a slow foetal heart rate $(90-120$ beats per minute) $(P=0.0069)$. It was also apparent that the presence of meconium alone did not significantly affect the babies' condition at birth, as the distribution of Apgar scores was similar to the control group. One unexpected finding was the significantly higher Apgar scores associated with a foetal heart rate of $90-120$ beats per minute compared with the control group $(\mathrm{P}<0.05)$.

TABLE IV.-Relation Between Clinical Criteria of Foetal Distress and Apgar Score of Babies Two Minutes After Birth

\begin{tabular}{|c|c|c|}
\hline Group & $\begin{array}{l}\text { Mean Apgar } \\
\text { Score }\end{array}$ & No. \\
\hline 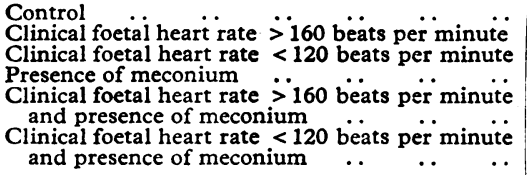 & $\begin{array}{l}7 \cdot 0 \\
5 \cdot 5 \\
7 \cdot 9 \\
7 \cdot 1 \\
5 \cdot 0 \\
6 \cdot 8\end{array}$ & $\begin{array}{l}29 \\
11 \\
10 \\
53 \\
27 \\
14\end{array}$ \\
\hline
\end{tabular}

\section{Discussion}

Auscultation of the foetal heart rate by the hospital staff showed both a random and a biased error. Because the hospital is a training school for midwives and obstetricians it may be thought that these errors were due to inexperience. However, Hon (1958) showed that similar errors occurred when consultant obstetricians counted the foetal heart rate. That experience may not be an important factor determining error is suggested by the better results obtained in the present study by two of us (E. D. and L. M.), both being medical students. While our greater accuracy may be due partly to our motivation in carrying out the study, it is thought that the technique of 
auscultation can be better taught by explaining the nature of possible errors. A foetal heart rate monitor provides the most effective method for teaching auscultation, as the staff. can check their own observations accurately and repeatedly. Nevertheless, the importance of foetal heart rate changes in relation to uterine contractions and the difficulty of detecting these changes by auscultation limits the usefulness of clinical measurement of the foetal heart rate. However, it is sometimes possible to count the foetal heart rate during contractions, and slowing at the end of the uterine contraction was detected in two patients, the observations being confirmed by the monitor record of heart rate.

The method of counting the foetal heart rate introduced by Caldeyro-Barcia et al. (1966) has merit. The counting is begun during or immediately before a contraction, and is continued until two minutes after the contraction, the count being taken over 15 -second periods with five-second intervals. This technique might involve the observer in making as many as 10 separate counts, and a more realistic schedule in our own hospital would be six counts each of 15 seconds, two taken during the contraction and four spaced over the two minutes after the contraction. In this manner change in the foetal heart rate may be detected both during and immediately after the contraction.

With clinical auscultation a rapid foetal heart rate was found important. The reason for the association of a rapid baseline foetal heart rate with depressed babies at birth was apparent when the monitored foetal heart rate was examined in the same patients. The majority of foetal heart rates showing changes in relation to a contraction which are associated with a poor prognosis for the foetus (type 3 ) were also rapid between contractions. An unusual finding in the present study was the normal Apgar scores associated with a steady baseline foetal heart rate of 100-120 beats per minute. However, a slow but steadily decreasing foetal heart rate may be significant, as evidenced in the following case.

The patient, 35 weeks pregnant, had clinical evidence of foetal growth retardation, a reduced urinary excretion of oestriol, and at artificial rupture of the membranes a low foetal scalp blood $\mathrm{pH}$ 7.13. Early in labour the clinical foetal heart rate was normal, while the monitor showed that the foetal heart rate slowed towards the end of contractions. One hour before delivery auscultation revealed a foetal heart rate of fewer than 120 beats per minute, and five minutes before delivery the rate fell to fewer than 100 beats per minute. Subsequently the baby was stillborn. The monitor confirmed the occurrence of a steadily worsening bradycardia over the hour before delivery.

Thus when relying on auscultation of the foetal heart rate the constant slow foetal heart rate must be distinguished from the slow but declining foetal heart rate.

We wish to thank the medical and nursing staff of the Queen Victoria Hospital for helping us carry out this study.

\section{REFERENCES}

Beard, R. W., Morris, E. D., and Clayton, S. G. (1967). f. Obstet. Gynaec. Brit. Cwlth, 74, 812 .

Caldeyro-Barcia, R., et al. (1966). In The Heart and Circulation in the Newborn and Infant, edited by D. E. Cassels, p. 7. New York.

Hon, E. H. (1958). Amer. F. Obstet. Gynec., 75, 1215.

Hon, E. H. (1960). Conn. med. F., 24, 289.

Hon, E. H. (1967). Fifth World Congress of Obstetrics and Gynaecology, Sydney, edited by C. Wood, p. 58. Sydney.

Saling, E. (1967). Fifth World Congress of Obstetrics and Gynaecology, Sydney, edited by C. Wood, p. 89 . Sydney.

Wood, C. (1968). In Prenatal Life-its Biological and Clinical Perspectives. Illinois. In press.

Wood, C., Ferguson, R., Leeton, J., Newman, W., and Walker, A. (1967). Amer. F. Obstet. Gynec., 98, 62 .

Wood, C., Newman, W., Lumley, J., and Hammond, J. (1968). Amer. F. Obstet. Gynec. In press.

Wood, C., and Pinkerton, J. H. M. (1961). 7. Obstet. Gynaec. Brit. Cwlth, 68, 552 .

\title{
Gastric Acid Secretion in Chronic Uraemia and after Renal Transplantation
}

\author{
J. C. GINGELL,* M.B., B.CH., F.R.C.S., F.R.C.S.ED. ; G. P. BURNS, †§ M.CH., F.R.C.S., F.R.C.S.ED. \\ G. D. CHISHOLM, $\ddagger$ CH.M., F.R.C.S., F.R.C.S.ED.
}

Brit. med. F., 1968, 4, 424-426

Cummary : In 45 patients with chronic uraemia the $\checkmark$ basal acid output was the same as in 22 controls. Maximal acid output in uraemic patients was less than in the controls but not significantly so. In uraemia the maximal acid output was directly related to the duration of uraemia and inversely related to both haemoglobin level and age ; it was not related to the height of the blood urea. Neutralization of ga tric acid by ammonia probably occurred in the basal juice, but not when acid secretion was maximally stimulated. The presence of secondary hyperparathyroidism was associated with a $\mathbf{5 0} \%$ increase in the maximal acid output, but the increase may have been due to the younger age of this group.

Successful renal transplantation was followed in two out of seven patients by a considerable increase in acid output and both patients showed evidence of peptic ulceration.

* Registrar.

t Senior Registrar.

¥ Consultant Urological Surgeon

Departments of Surgery and Urology, Hammersmith Hospital and Royal Postgraduate Medical School, London W.12.

S Present address: E. J. Meyer Memorial Hospital, Buffalo, New York.

\section{Introduction}

Patients with chronic uraemia may have a low gastric acid secretion in response to submaximal histamine stimulation (Lieber and Lefèvre, 1959). This hypoacidity has been attributed to neutralization of acid by the increased ammonia in the gastric juice known to occur in chronic uraemia. Reversal of the uraemic state by successful renal transplantation might permit an increase in gastric acid output, and such an increase could contribute to the development of peptic ulceration, which is recognized as a serious complication following renal transplantation (Calne, 1967 ; Pichlmaier et al., 1968).

We have therefore measured gastric acid secretion in patients with chronic uraemia to determine whether hyposecretion of acid occurs during maximal histamine stimulation. In addition we have examined the effect of successful renal transplantation on gastric acid output.

\section{Method and Patients}

Basal and maximal outputs of acid were measured in 45 patients (30 males and 15 females) with chronic uraemia. The 